\title{
B-cell activating factor targeted therapy and lupus
}

Alexis Boneparth¹ and Anne Davidson*2

\begin{abstract}
B-cell activating factor (BAFF), a member of the family of TNF-like cytokines, supports the survival and differentiation of B cells. The successful development of belimumab, a human antibody targeting soluble BAFF, has marked an important milestone in the development of biologic therapy for treatment of systemic lupus erythematosus (SLE), although much remains unknown regarding the clinical utility of BAFF inhibition in SLE and other autoimmune diseases. In the present review, we provide an overview of the knowledge concerning BAFF's role in murine and human B-cell development and maturation, as well as the clinical and mechanistic effects of BAFF inhibition in human SLE.
\end{abstract}

\section{B-cell activating factor and a proliferation- inducing ligand: novel therapeutic targets in autoimmune disease}

B-cell activating factor (BAFF) and a proliferationinducing ligand (APRIL) are homologous TNF-like cytokines that support the survival and differentiation of B cells. BAFF binds to three receptors - B-cell activating factor receptor (BAFF-R), transmembrane activator and calcium-modulator and cyclophilin ligand interactor (TACI), and B-cell maturation antigen (BCMA) - that are expressed on $B$ cells at different developmental stages, whereas APRIL binds only to TACI and BCMA. BAFF-R is the predominant receptor on transitional, naive, and memory $\mathrm{B}$ cells, TACI the predominant receptor on marginal zone and short-lived plasma cells, and BCMA the predominant receptor on long-lived plasma cells (reviewed [1-3]).

BAFF overexpression leads to B-cell expansion and a lupus-like syndrome in mice, whereas BAFF inhibition delays lupus onset in spontaneous mouse models of

\footnotetext{
*Correspondence: adavidson1@nshs.edu

${ }^{2}$ Center for Autoimmunity and Musculoskeletal Diseases, Feinstein Institute for

Medical Research, 350 Community Drive, Manhasset, NY 11030, USA

Full list of author information is available at the end of the article
}

systemic lupus erythematosus (SLE) [4-6]. These observations rapidly led to the development of therapeutics that inhibit BAFF and APRIL. The recent successful completion of two large, phase III clinical trials (BLISS-52 and BLISS-76) $[7,8]$ of belimumab, a human antibody targeting BAFF [9], and its approval for the treatment of SLE represent the first successful development of a novel biologic therapy for this disease. Moreover, clinical data regarding the effect of BAFF inhibition on B-cell subsets and serologic markers of disease activity have helped to elucidate the physiologic effects of BAFF inhibition in humans [10-12].

Enthusiasm for the use of belimumab in practice has been tempered for several reasons. In both of these phase III studies, the difference in primary outcome between standard of care and standard of care plus belimumab was modest and, in the BLISS-76 study, failed to be sustained at 76 weeks. Also, the mechanism by which belimumab benefits lupus patients is still not entirely clear, making it difficult to predict which patients will respond and how best to evaluate a therapeutic response. Finally, the expense of this new drug gives pause to prescribers and patients alike.

\section{Role of BAFF and BAFF inhibition in B-cell development, activation, and autoantibody production: lessons from murine studies}

Autoreactive B-cell receptors are generated either when random immunoglobulin variable gene rearrangement occurs in the bone marrow or as a consequence of somatic mutation that occurs mainly in the germinal centers after antigen stimulation [13]. Transitional $B$ cells, having exited from the bone marrow, depend both on a signal through the B-cell receptor and the interaction of BAFF with BAFF-R for their further maturation into follicular or marginal zone B cells $[14,15]$. In murine lupus models, BAFF inhibition depletes these cell types while sparing early transitional B cells and B1 cells $[16,17]$ (Figure 1). Because developing B cells that recognize autoantigen downregulate their expression of the Bcell receptor, they are relatively more dependent on BAFF than their nonautoreactive counterparts and are more likely to be deleted when serum levels of BAFF are limiting $[18,19]$. Importantly, however, not all developing autoreactive B cells are equally susceptible to BAFF 


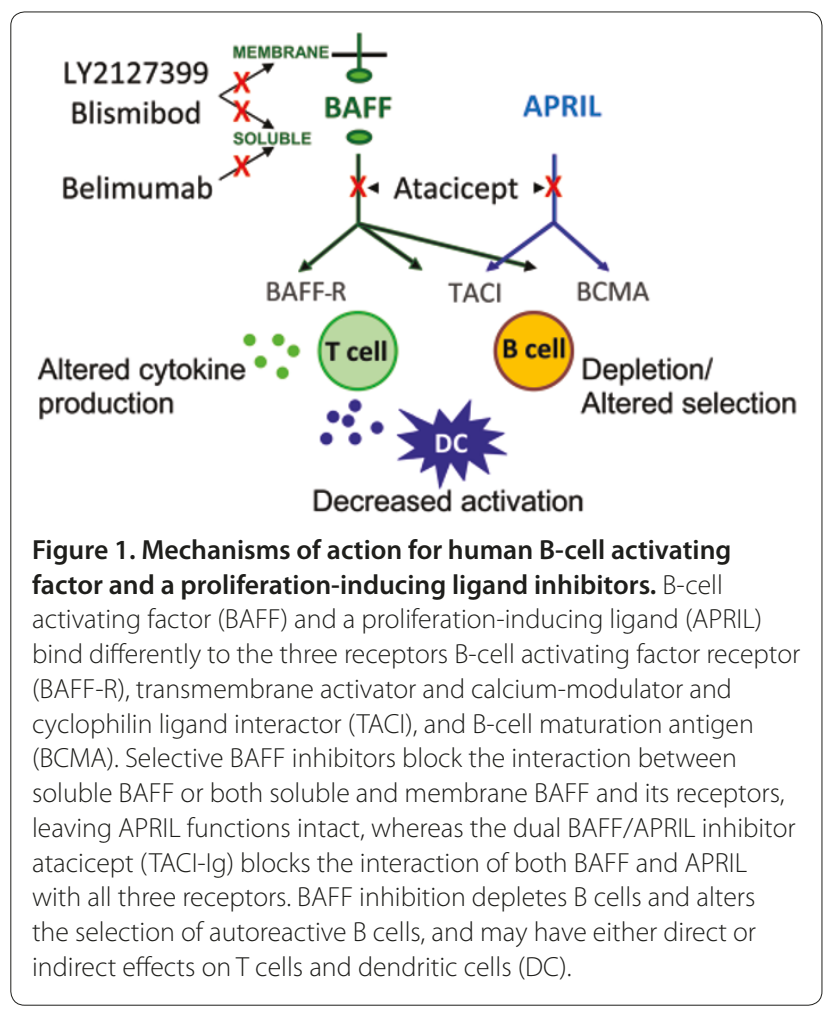

inhibition and the consequence of altering BAFF availability can vary depending on the B-cell environment and the proportion of autoreactive B cells compared with nonautoreactive B cells (reviewed [20]).

After antigen exposure, signaling through BAFF-R is necessary for the formation of a mature follicular dendritic cell network in germinal centers and for the survival of late germinal center B cells [21-23]. BAFF signals also interact with Toll-like receptor-mediated signals by a variety of mechanisms that serve to amplify immune responses [24-28]. Although both primary and secondary IgG responses are diminished by BAFF or BAFF- $R$ deficiency, class-switched and somatically mutated antibodies still arise after immunization [23]. In mouse models of lupus, BAFF inhibition only modestly delays the onset of an anti-double-stranded DNA autoantibody response and these antibodies are still capable of deposition in the kidneys $[16,17]$. Nevertheless, a complete absence of BAFF in a lupus-prone mouse strain skews the isotype of the glomerular IgG deposits [29], suggesting that BAFF may directly or indirectly play a role in the selection and maturation of germinal center and postgerminal center autoreactive B cells. Further work is needed to clarify this issue.

In mice, short-term selective BAFF blockade modestly decreases the number of short-lived IgM-producing plasma cells but has no effect on long-lived plasma cells because APRIL signaling through BCMA compensates for BAFF deficiency [30,31]. TACI-Ig that blocks both BAFF and APRIL profoundly reduces short-lived IgMproducing plasma cells and decreases the frequency of and total number of IgG-producing plasma cells in the spleen $[16,17]$. IFN $\alpha$ administration decreases the dependence of IgG-producing but not IgM-producing plasma cells on BAFF and APRIL [32]. While blockade of both BAFF and APRIL also decreases long-lived plasma cell survival in normal mice [33], bone marrow plasma cells in some strains of SLE mice are resistant to this blockade [34]. T cells may be a source of plasma cell support in the bone marrow since combined BAFF/APRIL inhibition and CTLA4-Ig treatment decreases serum levels of IgG, whereas neither drug alone has an effect [16].

Multiple innate and adaptive factors may thus influence the survival of plasma cells in the setting of chronic inflammation and alter their dependence on BAFF and APRIL [35]. In humans, IgM-producing and IgA-producing plasma cells are similarly more sensitive to BAFF/ APRIL blockade than are IgG-producing plasma cells $[36,37]$. The mechanism for this difference, whether it is intrinsic to the switched cells themselves or to their environment, is not known.

In experiments using immunization with conventional antigens, survival of murine memory B cells in vivo and of human memory B cells in vitro [38] was found to be independent of BAFF and APRIL signaling [16,30,31]. Whether there is any influence of BAFF or APRIL on selection or expansion of autoreactive memory B cells is not known. Since BAFF may collaborate with inflammatory cytokines in the reactivation of memory B cells, BAFF could conceivably play a role in memory B-cell function in inflammatory states $[39,40]$.

\section{BAFF inhibition: evaluation of efficacy in patients with SLE}

An initial phase II study of belimumab combined with standard of care therapy for treatment of SLE failed its primary endpoints - namely Safety of Estrogens in Lupus Erythematosus National Assessment (SELENA)-Systemic Lupus Erythematosus Disease Activity Index (SLEDAI) score reduction at week 24 , or a reduction in the time to first SLE flare over 52 weeks [12]. Nevertheless, the study provided valuable insights into belimumab's potential benefits and mechanism of action, and facilitated optimization of further trial design. By post-hoc analysis, time to first flare starting at week 24 through week 52 was significantly longer in the belimumab group than in the control group, suggesting that belimumab can stabilize disease but requires some time to do so. Posthoc analysis also identified a subset of autoantibodypositive patients (antinuclear antibody titer $\geq 1: 80$ and/or anti-double-stranded DNA antibody level $\geq 30 \mathrm{IU} / \mathrm{ml}$ ) in whom belimumab treatment was associated with 
Table 1. Main outcomes of the BLISS-52 and BLISS-76 trials

\begin{tabular}{|c|c|c|c|}
\hline & Belimumab 10 mg/kg (\%) & Belimumab 1 mg/kg (\%) & Placebo (\%) \\
\hline SRI response rate at 52 weeks (BLISS-52) & $58(P=0.0006)$ & $51(P=0.0129)$ & 44 \\
\hline SRI response rate at 52 weeks (BLISS-76) & $43.2(P=0.017)$ & $40.6(P=0.089)$ & 33.5 \\
\hline SRI response rate at 76 weeks (BLISS-76) & $38.5(P=0.13)$ & $39.1(P=0.11)$ & 32.4 \\
\hline Prednisone dose reduced $\geq 25 \%$, to $\leq 7.5 \% \mathrm{mg} /$ day during weeks 40 to 52 (BLISS-52) & $19(P=0.0526)$ & $21(P=0.025)$ & 12 \\
\hline Prednisone dose reduced $\geq 25 \%$, to $\leq 7.5 \% \mathrm{mg} /$ day during weeks 40 to 52 (BLISS-76) & $17.5(P>0.05)$ & $19.2(P>0.05)$ & 12.7 \\
\hline
\end{tabular}

SRI, Systemic Lupus Erythematosus Responder Index.

significantly greater reductions in SELENA-SLEDAI scores from baseline to week $52(-28.8 \%$ in the combined belimumab group vs. $-14.2 \%$ in controls). Additional post-hoc analysis of the phase II results led to the development of the Systemic Lupus Erythematosus Responder Index (SRI), designed to reflect improvement in disease activity without worsening of the overall condition or the development of significant disease activity in a new organ system $[12,41]$. The SRI is defined as: $\geq 4$-point reduction in the SELENA-SLEDAI score; no new British Isles Lupus Activity Group A domain score or no more than one new British Isles Lupus Activity Group B domain score; and no deterioration from baseline in the physician's global assessment $\geq 0.3$ points. When the SRI was retrospectively applied to the phase II trial, belimumab treatment resulted in a significantly larger percentage of responders than standard of care alone ( $46 \%$ vs. $29 \%, P=0.006)$ (Table 1$)$.

Using the SRI response rate at 52 weeks as their primary endpoint, both the BLISS-52 [7] and BLISS-76 [8] trials demonstrated a significantly better response to belimumab plus standard therapy versus standard therapy alone in serologically active patients with moderately active SLE. In the BLISS-52 study, the SRI response rate was $58 \%$ for $10 \mathrm{mg} / \mathrm{kg}$ belimumab and $51 \%$ for $1 \mathrm{mg} / \mathrm{kg}$ belimumab, compared with $44 \%$ in the controls. In the BLISS-76 study, belimumab at $10 \mathrm{mg} / \mathrm{kg}$ met the primary efficacy endpoint at week 52, with an SRI response rate of $43.3 \%$ compared with $33.5 \%$ in controls. The response to $1 \mathrm{mg} / \mathrm{kg}$ belimumab in the BLISS-76 trial was not statistically significant. In the BLISS-76 trial, the SRI response rate was numerically higher with belimumab than in controls at week 76, but the differences were no longer statistically significant. Nevertheless a post-hoc analysis that applied a more stringent reduction in the SELENA-SLEDAI score revealed significant differences between the belimumab and control groups at several times between week 40 and week 76 . The trial's ability to discriminate between doses was possibly compromised at week 76 due to a $7 \%$ dropout rate in each patient group between weeks 52 and 76 or due to more liberal prednisone use in the control group.

Steroid-sparing effects were also observed in the two phase III trials. In the BLISS-52 study, greater proportions of patients receiving $10 \mathrm{mg} / \mathrm{kg}$ belimumab were able to reduce their prednisone dose by $>50 \%(28 \%$ vs. $18 \%$ in controls, $P=0.0122$ ) and fewer needed to increase their prednisone dose; consequently, the total prednisone dose was significantly higher in the controls from weeks 12 to 52 . In the BLISS-76 study, similar trends were observed although the differences did not reach statistical significance. Reductions in flares were also observed in both phase III trials. In the BLISS-52 trial, for patients treated with $10 \mathrm{mg} / \mathrm{kg}$ belimumab the time to first flare was significantly increased and the risk of developing a severe flare during 52 weeks was reduced by 40 to $50 \%$, compared with the control group. There were similar trends in the BLISS-76 trial, but significance was only achieved in the $1 \mathrm{mg} / \mathrm{kg}$ belimumab group.

\section{Mechanistic studies of belimumab}

The mechanistic data from clinical trials of belimumab have been mostly consistent with murine studies, although the physiologic response lags several weeks behind the rapid response in mice. In human subjects with SLE, belimumab treatment led to a significant decrease in naïve and transitional CD27- B-cell subsets, in the $\mathrm{CD}^{2} 7^{+} / \mathrm{IgM}^{+}$subset that includes the marginal zone B-cell subpopulation, and in the $\operatorname{IgD}^{-} / \mathrm{CD} 27^{-}$ population, a heterogeneous population that accumulates in SLE patients and contains both naïve and memory B cells. Class-switched CD27 ${ }^{+}$memory B cells were not decreased even after several years of treatment. Only a very modest decrease in plasma cells was observed after 1 year, predominantly accounted for by a decrease in IgM-producing plasma cells [10,12].

Pooled data from the BLISS-52 and BLISS-76 trials have been analyzed for changes in autoantibodies, immunoglobulin, and complement, and BLISS-76 patients were analyzed for changes in B-cell and T-cell populations and effects on prior vaccine-induced antibody levels [11,42]. Results of these analyses are summarized below.

In the BLISS-76 trial, belimumab treatment did not decrease $\mathrm{T}$ cells - but total B cells declined by $55 \%$ over the course of the study, with the most significant decline in the naïve B-cell subset ( $-76.3 \%$ vs. $3.4 \%$ in controls). There was an initial doubling of the $\mathrm{CD} 20^{+} / \mathrm{CD} 27^{+}$subset that includes memory B cells and human B1 cells [43-45] 
at 8 weeks of treatment, which then slowly returned to normal; this may be secondary to the release of memory B cells from secondary lymphoid organs or to expansion of the memory pool, or even the B1 cell pool, as a homeostatic response to B-cell depletion - although it is important to note that the effect of belimumab on B1 cells in humans has not been examined and is currently unknown. There was a modest decrease in activated $\mathrm{B}$ cells $(-49.1 \%$ vs. $-25.2 \%$ in controls $)$ that became significant at week 52. Plasmablasts were evaluated using either CD138 or CD27, which identify overlapping plasmablast subsets [46]. Fully differentiated plasma cells are rare in the circulation and cannot be readily evaluated using flow cytometric analysis of peripheral blood. Plasmablast frequency and number declined by week 8 and then stabilized for the rest of the study. This early decline might reflect a resetting of the plasmablast number due to the decrease in BAFF availability, leaving only APRIL to maintain homeostasis. Alternatively, a decrease in the number of B cells, a change in the kinetics of plasmablast production, maturation or traffic, or a decrease in disease activity could all contribute. Since correlation of declining plasmablast number with total immunoglobulin or autoantibody levels was not performed, the physiologic significance of this finding is not yet known. Additionally, one should stress that changes in B-cell subsets have not been correlated with clinical response.

Belimumab induced a modest $\leq 15 \%$ decrease in total IgG levels by week 8 of treatment that persisted through week 52. More significant decreases were noted in serum levels of IgA $(\sim 17 \%)$ and IgM $(\sim 30 \%)$ with no change in the controls. In both trials, improvement of complement levels was observed as early as 4 weeks after starting therapy and continued throughout the trial. In the BLISS-76 study, $51 \%$ of treated patients with low serum complement levels at baseline had normalized their complement levels by week 76 . Although more patients in the belimumab group converted from positive to negative titers of anti-DNA antibodies, most converters had initially low titers of antibodies (30 to $99 \mathrm{IU} / \mathrm{ml}$ ) with virtually no conversions in patients with higher autoantibody titers. When data from the two phase III trials were pooled there was a median percentage change in anti-DNA titers of $40.8 \%$ compared with $10.2 \%$ in the controls, with changes observed as early as week 8 . The physiologic meaning of this change is unclear since the number of patients with only low titers at baseline was not reported. Conversions from positive to negative were also noted for other autoantibody specificities including $\mathrm{Sm}$, ribosomal $\mathrm{P}$, and cardiolipin, although initial titers of antibodies were not reported.

A post-hoc analysis of pooled data from the BLISS -52 and BLISS-76 trials was performed to investigate whether clinical response correlated with biomarkers of disease. There was no correlation of baseline BAFF levels with SRI response at week 52 irrespective of therapy, showing that BAFF levels cannot be used to select patients for treatment. Those patients who had low C3 or C4 and positive titers of anti-DNA antibodies at baseline had significantly higher SRI response rates with belimumab $1 \mathrm{mg} / \mathrm{kg}(41.5 \%, P=0.002)$ and $10 \mathrm{mg} / \mathrm{kg}(51.5 \%$, $P<0.002)$ than with standard of care alone $(31.7 \%)$ and a decreased risk of severe flare. However, hypocomplementemia and anti-DNA antibodies are common features of active lupus, and thus the clinical applicability of this finding will probably be limited. Furthermore, among only belimumab-treated patients, modified SRI response rates were significantly greater in those with normalization of $\mathrm{C} 4$ at week 4 than in those without normalization (56\% vs. $44 \%, P=0.02)$. Normalization of C3 at weeks 4 and 8 was also associated with a significantly lower risk of severe flare irrespective of therapy, but these differences were not significant when the belimumabtreated group was examined on its own. Similarly, a decrease in anti-DNA titers at week 8 was not significantly associated with a decrease in the risk of severe flare. Patients with normalization of IgG after week 24 had significantly greater SRI response rates than patients without normalization, irrespective of treatment. These data, in sum, suggest that serologic responses are associated with a better outcome, as expected, but that only the C4 level appears to be a potential early biomarker for those patients more likely to respond to belimumab. Nevertheless, the clinical utility of $\mathrm{C} 4$ as a biomarker for response to belimumab may be limited, given the relatively small difference in rates of SRI response between $\mathrm{C} 4$ normalizers and non-normalizers and the relatively narrow range of $\mathrm{C} 4$ levels encountered in clinical practice.

In the BLISS-76 trial, changes in B-cell and plasma cell subsets over 52 weeks were evaluated for correlations with SRI response or reduction in flares. Only the naïve B-cell subset showed a consistent association of greater percentage reduction from baseline with greater likelihood of SRI response at week 52 (60.2\% vs. $46.0 \%$ SRI response rate with $>70 \%$ vs. $<70 \%$ reduction, $P=0.002$ ) and lower risk of severe flare over 52 weeks. This analysis held true irrespective of therapy, so the role of belimumab is unclear. Nevertheless, since B-cell depletion $>70 \%$ occurred more often in the belimumab group than in controls, the data suggest possible differences in pharmacokinetics of the drug between patients.

We conclude from these findings that currently there appear to be no effective biomarkers for the identification of individual patients who are likely to respond to belimumab therapy. 


\section{Safety of belimumab in the BLISS-52 and BLISS-76 trials}

Effects on pre-existing vaccine antigen-specific antibody levels were assessed in BLISS-76 patients who had received pneumococcal or tetanus vaccine within 5 years of the start of treatment. At week 52 there were no significant differences across treatment groups in the percentages of patients maintaining anti-pneumococcal IgG titers to five serotypes that cause frequent drugresistant pneumococcal infections in the United States. Similarly, anti-tetanus toxin IgG titers and anti-influenza titers were not significantly decreased [42]. In the BLISS-76 trial, one patient in each treatment group had a grade 3 reduction in total serum IgG ( $\operatorname{IgG}<4 \mathrm{~g} / \mathrm{l})$, which was not associated with infection. These data are consistent with those from the mouse studies that showed no effect of BAFF inhibition on long-lived class switched plasma cells.

In both the BLISS-52 and BLISS-76 trials, the incidence of adverse events - including laboratory abnormalities, serious infections, and malignancies - was similar in the treated and control groups. In the BLISS-76 study, infusion reactions were more common with belimumab than in controls (14 to $16 \%$ vs. $10 \%$ ) but all resolved with antihistamine and/or prednisone treatment on the day of the infusion. Five pregnancies occurred in patients receiving belimumab. Three of these pregnancies resulted in normal live births, one in elective termination, and one patient was lost to follow up. Several suicides were noted in the belimumab group but it is not clear whether these were drug related.

\section{Beyond the BLISS trials: clinical outlook and delineation of mechanism}

Much remains unknown regarding the clinical utility of BAFF inhibition in SLE. The BLISS-52 and BLISS-76 trials were not powered to compare belimumab treatment against the background of different immunosuppressive therapies. Additionally, some patient subpopulations were not evaluated - notably pediatric patients and patients with active lupus nephritis or cerebritis. Some of these issues are being addressed in ongoing studies. Given the time it takes to observe a therapeutic effect with belimumab, it is not a suitable intervention for acute severe flares. Whether belimumab should be used to prevent flares or as a steroid-sparing agent for patients with moderate disease activity remains to be determined in longer term studies. Determining the duration of the therapeutic effect is critical, because the observed reduction in number and severity of flares and a decreased overall steroid dose even at 76 weeks could all contribute to significant long-term benefits. Notably, the manufacturers do not recommend the as yet unevaluated use of belimumab following treatment with either cyclophosphamide or rituximab. Nevertheless, inhibiting BAFF after cyclophosphamide or rituximab treatment could potentially reverse the adverse effects of B-cell depletion on selection of naïve autoreactive B cells. The safety of this strategy remains to be evaluated. Further mechanistic studies may identify biomarkers for a therapeutic response and may help determine which patients are most likely to benefit from belimumab treatment.

Other strategies for inhibiting BAFF are available. Atacicept (a nonselective antagonist of both BAFF and APRIL) is in trial for the treatment of moderately active SLE. Tabalumab (LY2127399), an alternate anti-BAFF antibody, and blisibimod, a small BAFF-R-derived peptide, both of which block both soluble and membrane BAFF (in contrast to belimumab, which blocks only soluble BAFF), are similarly being tested in SLE [47] and whether there is a benefit of blocking both BAFF and APRIL or of blocking all BAFF forms over blocking soluble BAFF alone remains to be determined. Selective APRIL blockade has demonstrated very modest preventive effects in NZB/W mice, delaying proteinuria, kidney damage, and mortality by approximately 4 weeks, and with limited effects on B-cell kinetics or autoantibody titers [48]. APRIL ${ }^{-/-}$NZM2328 mice have clinically identical disease to wild-type NZM2328 mice, confirming that APRIL is minimally involved in disease development [49]. Selective APRIL inhibition is unlikely to be tested in human SLE.

BAFF overexpression has been detected in the brains of mice and patients with multiple sclerosis, and atacicept had a beneficial effect in a mouse model of multiple sclerosis. However, a phase II study of atacicept for multiple sclerosis had to be terminated because of disease worsening [47]. IFN $\beta$ is standard treatment for multiple sclerosis and increases serum BAFF levels in multiple sclerosis patients [50]. Whether the negative effect of atacicept was due to a decrease in type I interferon or an alteration in other cytokines has not been determined.

Data from animal and human studies suggests that BAFF inhibition could have therapeutic effects beyond its primary effect on B cells. BAFF supports the survival of monocytes and enhances their differentiation into macrophages [51]. Human myeloid dendritic cells stimulated with BAFF in vitro upregulate co-stimulatory molecules, lose their phagocytic ability, and produce inflammatory cytokines [52]. This effect may be due to interaction with dendritic cell-expressed TACI. T-cell production of IFNY is supported by the interaction of BAFF with BAFF-R on the surface of activated T cells; T cells from SLE patients produce more IFNY in response to BAFF than do T cells from normal individuals [53]. In a mouse model of arthritis, synovial dendritic cells transduced with a siRNA that silences BAFF remained in an immature state and failed to produce the IL- 6 required for the differentiation 
Table 2. Unanswered questions about B-cell activating factor inhibition

\begin{tabular}{ll}
\hline Clinical & Mechanistic \\
\hline $\begin{array}{l}\text { Comparative efficacy of belimumab with different background } \\
\text { immunosuppressive therapies }\end{array}$ & $\begin{array}{l}\text { Secondary therapeutic effects of BAFF inhibition beyond primary effects on } \\
\text { B cells }\end{array}$ \\
$\begin{array}{l}\text { Belimumab utility in unstudied patient populations (pediatric lupus, } \\
\text { nephritis, cerebritis) }\end{array}$ & $\begin{array}{l}\text { Effect of BAFF inhibition on selection and maturation of naïve and } \\
\text { antigen-activated autoreactive B cells in humans }\end{array}$ \\
$\begin{array}{l}\text { Duration of therapeutic effect } \\
\text { Safety of belimumab post B-cell depletion }\end{array}$ \\
$\begin{array}{l}\text { Utility of atacicept, LY2127399, and other BAFF/APRIL-blocking therapies } \\
\text { for SLE and other autoimmune diseases }\end{array}$ \\
\hline
\end{tabular}

APRIL, a proliferation-inducing ligand; BAFF, B-cell activating factor; SLE, systemic lupus erythematosus.

of T-helper type 17 cells [54]. Peripheral monocytes from patients with Sjögren's syndrome produce significantly higher amounts of BAFF and IL-6 in comparison with normal monocytes, and this difference is partially suppressed by an anti-BAFF antibody $[55,56]$. Furthermore, salivary epithelial cells from Sjögren's syndrome patients can be induced by type I interferon to express BAFF [57]. BAFF can also bind to basophils, although the role of this interaction is still unknown [58].

More work must be done to elucidate the role of BAFF inhibition in regulating the contributions of these nonimmune B-cell types to autoantibody-initiated tissue inflammation, and to autoimmunity in general. Likewise, a better understanding of BAFF and APRIL and their varied contributions to both innate and adaptive immune system function holds promise for more effective and specific targeting of BAFF for the treatment of autoimmune diseases.

\section{Key messages}

- BAFF is a member of a family of TNF-like cytokines that have a number of immunoregulatory effects, including supporting the survival and differentiation of B cells.

- The successful development of belimumab, a human antibody targeting soluble BAFF, has marked an important milestone in the development of biologic therapy for treatment of SLE.

- In two large, phase III trials of belimumab combined with standard therapy, treated patients had a better outcome at 1 year than patients treated with standard therapy alone, including a difference in the number of patients achieving the SRI, a reduction in the risk of flares and severe flares, and an overall reduction in prednisone use.

- In groups of belimumab-treated patients, clinical improvements were accompanied by significant and sustained improvements in measures of serologic activity compared with placebo-treated patients. However, monitoring for response to belimumab therapy in individual patients remains problematic.
- It is not clear whether any therapeutic effect of belimumab is maintained beyond week 76 .

- Data from clinical trials of belimumab demonstrate similarity between the mechanistic effects of BAFF inhibition on murine and human B-cell populations.

- Other drugs targeting both soluble and membrane BAFF and both BAFF and the homologous molecule APRIL are currently undergoing clinical trials.

- Much remains unknown regarding the clinical utility of BAFF inhibition in SLE and other autoimmune diseases (Table 2).

\section{Abbreviations}

APRIL, a proliferation-inducing ligand; BAFF, B-cell activating factor; BAFF-R, B-cell activating factor receptor; BCMA, B-cell maturation antigen; IFN, interferon; Ig, immunoglobulin; IL, interleukin; SELENA, Safety of Estrogens in Lupus Erythematosus National Assessment; siRNA, small interfering RNA; SLE, systemic lupus erythematosus; SLEDAI, Systemic Lupus Erythematosus Disease Activity Index; SRI, Systemic Lupus Erythematosus Responder Index; TACl, transmembrane activator and calcium-modulator and cyclophilin ligand interactor; TNF, tumor necrosis factor.

\section{Competing interests}

The authors declare that they have no competing interests.

\section{Declarations}

This article has been published as part of Arthritis Research \& Therapy Volume 14 Suppl 4, 2012: New therapeutic targets in systemic lupus erythematosus. The supplement was proposed and developed by the journal. Articles were commissioned by the journal, were independently prepared by the authors and have undergone the journal's standard peer review process. Publication of the supplement has been supported by an unrestricted educational grant from UCB. Completed articles underwent a data quality check by Darwin Healthcare Communications, funded by UCB

\section{Author details}

'Department of Pediatrics, Albert Einstein College of Medicine, 1300 Morris Park Avenue, Bronx, NY 10461, USA. ${ }^{2}$ Center for Autoimmunity and Musculoskeletal Diseases, Feinstein Institute for Medical Research, 350 Community Drive, Manhasset, NY 11030, USA

Published: 2 November 2012

\section{References}

1. Davidson A: Targeting BAFF in autoimmunity. Curr Opin Immunol 2010, 22:732-739.

2. Mackay F, Figgett WA, Saulep D, Lepage M, Hibbs ML: B-cell stage and context-dependent requirements for survival signals from BAFF and the B-cell receptor. Immunol Rev 2010, 237:205-225.

3. Mackay F, Schneider P: Cracking the BAFF code. Nat Rev Immunol 2009, 
9:491-502.

4. Gross JA, Johnston J, Mudri S, Enselman R, Dillon SR, Madden K, Xu W, ParrishNovak J, Foster D, Lofton-Day C, Moore M, Littau A, Grossman A, Haugen H, Foley K, Blumberg H, Harrison K, Kindsvogel W, Clegg CH: TACl and BCMA are receptors for a TNF homologue implicated in B-cell autoimmune disease. Nature 2000, 404:995-999.

5. Khare SD, Sarosi I, Xia XZ, McCabe S, Miner K, Solovyev I, Hawkins N, Kelley M, Chang D, Van G, Ross L, Delaney J, Wang L, Lacey D, Boyle WJ, Hsu H: Severe B cell hyperplasia and autoimmune disease in TALL-1 transgenic mice. Proc Natl Acad Sci U S A 2000, 97:3370-3375.

6. Moore PA, Belvedere O, Orr A, Pieri K, LaFleur DW, Feng P, Soppet D, Charters M, Gentz R, Parmelee D, Li Y, Galperina O, Giri J, Roschke V, Nardelli B, Carrell J, Sosnovtseva S, Greenfield W, Ruben SM, Olsen HS, Fikes J, Hilbert DM: BLyS: member of the tumor necrosis factor family and B lymphocyte stimulator. Science 1999, 285:260-263.

7. Navarra SV, Guzman RM, Gallacher AE, Hall S, Levy RA, Jimenez RE, Li EK, Thomas M, Kim HY, Leon MG, Tanasescu C, Nasonov E, Lan JL, Pineda L, Zhong ZJ, Freimuth W, Petri MA: Efficacy and safety of belimumab in patients with active systemic lupus erythematosus: a randomised, placebo-controlled, phase 3 trial. Lancet 2011, 377:721-731.

8. Furie R, Petri M, Zamani O, Cervera R, Wallace DJ, Tegzova D, SanchezGuerrero J, Schwarting A, Merrill JT, Chatham WW, StohI W, Ginzler EM, Hough DR, Zhong ZJ, Freimuth W, van Vollenhoven RF: A phase III, randomized, placebo-controlled study of belimumab, a monoclonal antibody that inhibits B lymphocyte stimulator, in patients with systemic lupus erythematosus. Arthritis Rheum 2011, 63:3918-3930.

9. Baker KP, Edwards BM, Main SH, Choi GH, Wager RE, Halpern WG, Lappin PB, Riccobene T, Abramian D, Sekut L, Sturm B, Poortman C, Minter RR, Dobson CL, Williams E, Carmen S, Smith R, Roschke V, Hilbert DM, Vaughan TJ, Albert VR: Generation and characterization of LymphoStat-B, a human monoclonal antibody that antagonizes the bioactivities of B lymphocyte stimulator. Arthritis Rheum 2003, 48:3253-3265

10. Jacobi AM, Huang W, Wang T, Freimuth W, Sanz I, Furie R, Mackay M, Aranow C, Diamond B, Davidson A: Effect of long-term belimumab treatment on $B$ cells in systemic lupus erythematosus: extension of a phase II, doubleblind, placebo-controlled, dose-ranging study. Arthritis Rheum 2010, 62:201-210

11. Stohl W, Hiepe F, Latinis KM, Thomas M, Scheinberg MA, Clarke A, Aranow C, Wellborne FR, Abud-Mendoza C, Hough DR, Pineda L, Migone TS, Zhong ZJ, Freimuth WW, Chatham WW: Belimumab reduces autoantibodies, normalizes low complement, and reduces select B-cell populations in patients with systemic lupus erythematosus. Arthritis Rheum 2012 64:2328-2337

12. Wallace DJ, StohI W, Furie RA, Lisse JR, McKay JD, Merrill JT, Petri MA, Ginzler EM, Chatham WW, McCune WJ, Fernandez V, Chevrier MR, Zhong ZJ, Freimuth WW: A phase II, randomized, double-blind, placebo-controlled, dose-ranging study of belimumab in patients with active systemic lupus erythematosus. Arthritis Rheum 2009, 61:1168-1178.

13. Goodnow CC, Vinuesa CG, Randall KL, Mackay F, Brink R: Control systems and decision making for antibody production. Nat Immunol 2010, 11:681-688.

14. Cancro MP, D'Cruz DP, Khamashta MA: The role of B lymphocyte stimulator (BLyS) in systemic lupus erythematosus. J Clin Invest 2009, 119:1066-1073.

15. Stadanlick JE, Cancro MP: BAFF and the plasticity of peripheral B cell tolerance. Curr Opin Immunol 2008, 20:158-161.

16. Ramanujam M, Wang X, Huang W, Schiffer L, Grimaldi C, Akkerman A, Diamond B, Madaio MP, Davidson A: Mechanism of action of transmembrane activator and calcium modulator ligand interactor-lg in murine systemic lupus erythematosus. J Immuno/ 2004, 173:3524-3534.

17. Ramanujam M, Wang X, Huang W, Liu Z, Schiffer L, Tao H, Frank D, Rice J, Diamond B, Yu KO, Porcelli S, Davidson A: Similarities and differences between selective and nonselective BAFF blockade in murine SLE. J Clin Invest 2006, 116:724-734.

18. Thien M, Phan TG, Gardam S, Amesbury M, Basten A, Mackay F, Brink R: Excess BAFF rescues self-reactive $B$ cells from peripheral deletion and allows them to enter forbidden follicular and marginal zone niches. Immunity 2004, 20:785-798.

19. Lesley R, Xu Y, Kalled SL, Hess DM, Schwab SR, Shu HB, Cyster JG: Reduced competitiveness of autoantigen-engaged $B$ cells due to increased dependence on BAFF. Immunity 2004, 20:441-453.

20. Liu Z, Davidson A: BAFF and selection of autoreactive B cells. Trends Immunol 2011, 32:388-394.
21. Kalled SL: Impact of the BAFF/BR3 axis on B cell survival, germinal center maintenance and antibody production. Semin Immunol 2006, 18:290-296.

22. Vora KA, Wang LC, Rao SP, Liu ZY, Majeau GR, Cutler AH, Hochman PS, Scott $M L$, Kalled SL: Cutting edge: germinal centers formed in the absence of $B$ cell-activating factor belonging to the TNF family exhibit impaired maturation and function. J Immuno/ 2003, 171:547-551.

23. Rahman ZS, Rao SP, Kalled SL, Manser T: Normal induction but attenuated progression of germinal center responses in BAFF and BAFF-R signalingdeficient mice. J Exp Med 2003, 198:1157-1169.

24. Hardenberg G, Planelles L, Schwarte CM, van Bostelen L, Le Huong T, Hahne M, Medema JP: Specific TLR ligands regulate APRIL secretion by dendritic cells in a PKR-dependent manner. Eur J Immuno/ 2007, 37:2900-2911.

25. Groom JR, Fletcher CA, Walters SN, Grey ST, Watt SV, Sweet MJ, Smyth MJ, Mackay CR, Mackay F: BAFF and MyD88 signals promote a lupuslike disease independent of T cells. J Exp Med 2007, 204:1959-1971.

26. Acosta-Rodriguez EV, Craxton A, Hendricks DW, Merino MC, Montes CL, Clark EA, Gruppi A: BAFF and LPS cooperate to induce B cells to become susceptible to CD95/Fas-mediated cell death. Eur J Immuno/ 2007, 37:990-1000.

27. He B, Santamaria R, Xu W, Cols M, Chen K, Puga I, Shan M, Xiong H, Bussel JB, Chiu A, Puel A, Reichenbach J, Marodi L, Doffinger R, Vasconcelos J, Issekutz A, Krause J, Davies G, Li X, Grimbacher B, Plebani A, Meffre E, Picard C, Cunningham-Rundles C, Casanova JL, Cerutti A: The transmembrane activator $\mathrm{TACl}$ triggers immunoglobulin class switching by activating $\mathrm{B}$ cells through the adaptor MyD88. Nat Immuno/ 2010, 11:836-845.

28. Katsenelson N, Kanswal S, Puig M, Mostowski H, Verthelyi D, Akkoyunlu M: Synthetic CpG oligodeoxynucleotides augment BAFF- and APRILmediated immunoglobulin secretion. Eur J Immuno/ 2007, 37:1785-1795.

29. Jacob CO, Pricop L, Putterman C, Koss MN, Liu Y, Kollaros M, Bixler SA, Ambrose CM, Scott ML, StohI W: Paucity of clinical disease despite serological autoimmunity and kidney pathology in lupus-prone New Zealand mixed 2328 mice deficient in BAFF. J Immuno/ 2006, 177:2671-2680.

30. Benson MJ, Dillon SR, Castigli E, Geha RS, Xu S, Lam KP, Noelle RJ: Cutting edge: the dependence of plasma cells and independence of memory B cells on BAFF and APRIL. J Immunol 2008, 180:3655-3659.

31. Scholz JL, Crowley JE, Tomayko MM, Steinel N, O'Neill PJ, Quinn WJ, 3rd, Goenka R, Miller JP, Cho YH, Long V, Ward C, Migone TS, Shlomchik MJ, Cancro MP: BLyS inhibition eliminates primary B cells but leaves natural and acquired humoral immunity intact. Proc Natl Acad Sci U S A 2008 105:15517-15522.

32. Liu Z, Bethunaickan R, Huang W, Lodhi U, Solano I, Madaio MP, Davidson A Interferon-alpha accelerates murine systemic lupus erythematosus in a T cell-dependent manner. Arthritis Rheum 2011, 63:219-229.

33. O'Connor BP, Raman VS, Erickson LD, Cook WJ, Weaver LK, Ahonen C, Lin LL, Mantchev GT, Bram RJ, Noelle RJ: BCMA is essential for the survival of longlived bone marrow plasma cells. J Exp Med 2004, 199:91-98.

34. Liu Z, Zou Y, Davidson A: Plasma cells in systemic lupus erythematosus: the long and short of it all. Eur J Immunol 2011, 41:588-591.

35. Davidson A: BAFF, APRIL and plasma cells. Int J Clin Rheum 2010, 5:281-285.

36. Dall'Era M, Chakravarty E, Wallace D, Genovese M, Weisman M, Kavanaugh A, Kalunian K, Dhar P, Vincent E, Pena-Rossi C, Wofsy D: Reduced B lymphocyte and immunoglobulin levels after atacicept treatment in patients with systemic lupus erythematosus: results of a multicenter, phase lb, doubleblind, placebo-controlled, dose-escalating trial. Arthritis Rheum 2007, 56:4142-4150

37. Pena-Rossi C, Nasonov E, Stanislav M, Yakusevich V, Ershova O, Lomareva N, Saunders H, Hill J, Nestorov I: An exploratory dose-escalating study investigating the safety, tolerability, pharmacokinetics and pharmacodynamics of intravenous atacicept in patients with systemic lupus erythematosus. Lupus 2009, 18:547-555.

38. Avery DT, Kalled SL, Ellyard JI, Ambrose C, Bixler SA, Thien M, Brink R, Mackay F, Hodgkin PD, Tangye SG: BAFF selectively enhances the survival of plasmablasts generated from human memory B cells. J Clin Invest 2003, 112:286-297.

39. Doreau A, Belot A, Bastid J, Riche B, Trescol-Biemont MC, Ranchin B, Fabien N, Cochat P, Pouteil-Noble C, Trolliet P, Durieu I, Tebib J, Kassai B, Ansieau S, Puisieux A, Eliaou JF, Bonnefoy-Berard N: Interleukin 17 acts in synergy with $B$ cell-activating factor to influence $B$ cell biology and the pathophysiology of systemic lupus erythematosus. Nat Immunol 2009, 10:778-785. 
40. Ettinger R, Sims GP, Robbins R, Withers D, Fischer RT, Grammer AC, Kuchen S, Lipsky PE: IL-21 and BAFF/BLyS synergize in stimulating plasma cell differentiation from a unique population of human splenic memory B cells. J Immuno/ 2007, 178:2872-2882.

41. Furie RA, Petri MA, Wallace DJ, Ginzler EM, Merrill JT, Stohl W, Chatham WW, Strand V, Weinstein A, Chevrier MR, Zhong ZJ, Freimuth WW: Novel evidencebased systemic lupus erythematosus responder index. Arthritis Rheum 2009, 61:1143-1151.

42. Chatham WW, Wallace DJ, StohI W, Latinis KM, Manzi S, McCune WJ, Tegzova D, McKay JD, Avila-Armengol HE, Utset TO, Zhong ZJ, Hough DR, Freimuth WW, Migone TS: Effect of belimumab on vaccine antigen antibodies to influenza, pneumococcal, and tetanus vaccines in patients with systemic lupus erythematosus in the BLISS-76 trial. J Rheumatol 2012, 39:1632-1640.

43. Jacobi AM, Zhang J, Mackay M, Aranow C, Diamond B: Phenotypic characterization of autoreactive $B$ cells - checkpoints of $B$ cell tolerance in patients with systemic lupus erythematosus. PLoS One 2009, 4:e5776.

44. Griffin DO, Holodick NE, Rothstein TL: Human B1 cells in umbilical cord and adult peripheral blood express the novel phenotype CD20+CD27+CD43+CD70.J Exp Med 2011, 208:67-80.

45. Griffin DO, Rothstein TL: A small CD1 $1 \mathrm{~b}^{+}$human $B 1$ cell subpopulation stimulates T cells and is expanded in lupus. J Exp Med 2011, 208:2591-2598.

46. Jacobi AM, Mei H, Hoyer BF, Mumtaz IM, Thiele K, Radbruch A, Burmester GR, Hiepe F, Dorner T: HLA-DR high/CD27 $7^{\text {high }}$ plasmablasts indicate active disease in patients with systemic lupus erythematosus. Ann Rheum Dis 2010, 69:305-308

47. ClinicalTrials.gov [www.clinicaltrials.gov]

48. Huard B, Tran NL, Benkhoucha M, Manzin-Lorenzi C, Santiago-Raber ML: Selective APRIL blockade delays systemic lupus erythematosus in mouse. PLoS One 2012, 7:e31837.

49. Jacob CO, Guo S, Jacob N, Pawar RD, Putterman C, Quinn WJ, 3rd, Cancro MP, Migone TS, Stohl W: Dispensability of APRIL to the development of systemic lupus erythematosus in NZM 2328 mice. Arthritis Rheum 2012, 64:1610-1619.

50. Krumbholz M, Faber H, Steinmeyer F, Hoffmann LA, Kumpfel T, Pellkofer H, Derfuss T, lonescu C, Starck M, Hafner C, Hohlfeld R, Meinl E: Interferon-beta increases BAFF levels in multiple sclerosis: implications for B cell autoimmunity. Brain 2008, 131 (Pt 6):1455-1463.

51. Chang SK, Arendt BK, Darce JR, WU X, Jelinek DF: A role for BLyS in the activation of innate immune cells. Blood 2006, 108:2687-2694.

52. Chang SK, Mihalcik SA, Jelinek DF: B lymphocyte stimulator regulates adaptive immune responses by directly promoting dendritic cell maturation. J Immunol 2008, 180:7394-7403.

53. Scapini P, Hu Y, Chu CL, Migone TS, Defranco AL, Cassatella MA, Lowell CA: Myeloid cells, BAFF, and IFN- $\gamma$ establish an inflammatory loop that exacerbates autoimmunity in Lyn-deficient mice. J Exp Med 2010, 207:1757-1773.

54. Lai Kwan Lam Q, King Hung Ko O, Zheng BJ, Lu L: Local BAFF gene silencing suppresses Th17-cell generation and ameliorates autoimmune arthritis. Proc Natl Acad Sci U S A 2008, 105:14993-14998.

55. Lavie F, Miceli-Richard C, Ittah M, Sellam J, Gottenberg JE, Mariette X: B-cell activating factor of the tumour necrosis factor family expression in blood monocytes and T cells from patients with primary Sjogren's syndrome. Scand J Immunol 2008, 67:185-192.

56. Yoshimoto K, Tanaka M, Kojima M, Setoyama Y, Kameda H, Suzuki K, Tsuzaka K, Ogawa Y, Tsubota K, Abe T, Takeuchi T: Regulatory mechanisms for the production of BAFF and IL-6 are impaired in monocytes of patients of primary Sjogren's syndrome. Arthritis Res Ther 2011, 13:R170.

57. Ittah M, Miceli-Richard C, Eric Gottenberg J, Lavie F, Lazure T, Ba N, Sellam J, Lepajolec C, Mariette X: B cell-activating factor of the tumor necrosis factor family (BAFF) is expressed under stimulation by interferon in salivary gland epithelial cells in primary Sjogren's syndrome. Arthritis Res Ther 2006, 8:R51.

58. Charles N, Hardwick D, Daugas E, Illei GG, Rivera J: Basophils and the Thelper 2 environment can promote the development of lupus nephritis. Nat Med 2010, 16:701-707.

doi:10.1186/ar3920

Cite this article as: Boneparth A, Davidson A: B-cell activating factor targeted therapy and lupus. Arthritis Research \& Therapy 2012, 14(Suppl 4):S2. 